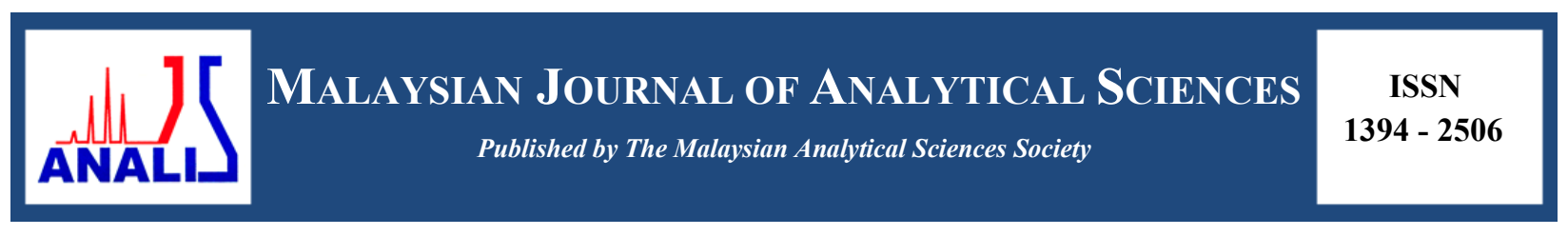

\title{
SURFACE PLASMON RESONANCE SENSOR FOR DETECTION OF PARATHION METHYL IN WATER
}

\author{
(Sensor Permukaan Plasmon Resonan bagi Pengesanan Parathion Metil di dalam Air) \\ Baisheng Chen ${ }^{1}$, Douglas Chiang Yon Chong ${ }^{1}$, Xiamin Cheng ${ }^{2,3}$, Bin Liu ${ }^{3}$, Sam Fong $\mathrm{Yau} \mathrm{Li}^{1,2 *}$ \\ ${ }^{l}$ Department of Chemistry, \\ National University of Singapore, 3 Science Drive 3, Singapore 117543, Singapore \\ ${ }^{2} N U S$ Environmental Research Institute (NERI), \\ \#02-01, T-Lab Building (TL), 5A Engineering Drive 1, Singapore 117411, Singapore \\ ${ }^{3}$ Department of Chemical \& Biomolecular Engineering, \\ National University of Singapore, 4 Engineering Drive 4, Block E5 \#02-17, 117585, Singapore \\ *Corresponding author: chmlifys@nus.edu.sg
}

Received: 7 November 2016; Accepted: 18 September 2017

\begin{abstract}
A surface plasmon resonance (SPR) sensor based on molecularly imprinted polymer (MIP) was developed for fast detection of chemical threat agents (CTAs) in water. A portable SPR platform provided a very compact-size ( $\mathrm{L}^{*} \mathrm{~W}^{*} \mathrm{H}$ of $8.5^{*} 4.5^{*} 4.5$ inch) system and the SPR sensor chip was fabricated by a facile process with an inexpensive coating of silver as the SPR material, making possible the sensor chip as a disposal sensor. Using methyl parathion as the simulant of CTA, the developed SPR sensor with the recognition site showed apparent SPR signal than Non-imprinted polymer (NIP) counterpart, suggesting the excellent recognition of the targeted molecules. It also provided a fast responding within 5 minutes with the limit of detection of sub-ppm level.
\end{abstract}

Keywords: molecularly imprinted polymer, surface plasmon resonance, organophosphorus pesticide, chemical threat agents

\section{Abstrak}

Sensor permukaan plasmon resonans (SPR) berdasarkan polimer molekul tercetak (MIP) telah dibangunkan bagi pengesanan pantas ejen ancaman kimia (CTAs) di dalam air. Sistem platform SPR mudah alih bersaiz padat disediakan $(\mathrm{L} * \mathrm{~W} * \mathrm{H} 8.5 * 4.5 * 4.5$ inci) dan cip sensor SPR telah diubahsuai melalui proses mudah dengan salutan murah perak sebagai bahan SPR, menjadikan cip sensor sebagai sensor mudah dilupuskan. Menggunakan parathion metil sebagai sasaran CTA, sensor SPR yang telah dibangunkan dengan bahagian yang dikenalpasti itu menunjukkan isyarat jelas daripada SPR berbanding polimer tak tercetak (NIP), menunjukkan pengenalpastian baik bagi molekul yang disasarkan. Ia juga memberi respons yang cepat dalam masa 5 minit dengan had pengesanan pada aras sub-ppm.

Kata kunci: polimer molekul tercetak, permukaan plasmon resonans, racun perosak organofosforus, agen kimia berbahaya

\section{Introduction}

The emerging concerns of terrorists using Chemical Threat Agents (CTAs) has been on the rise which has urged the governments to ensure the water safety before consumption [1,2]. Organophosphorus compounds (OPs) is used as the simulant of a type of chemical threat agents- nerve agents. The current monitoring method includes gas chromatography-mass spectrometry [3], liquid chromatography-mass spectrometry [4] and micellar electro-kinetic capillary electrophoresis coupled with laser-induced fluorescence (MEKC-LIF) detector [5]. However, these 

WATER

instruments involved in the monitoring are usually bulky in size, and highly expensive and require highly trained technicians to run the samples, which hinders the application of on-line or on-site monitoring [6]. An alternative monitoring technique is surface plasmon resonance (SPR), which is a phenomenon that occurs when the incident light on a metal film induces the propagation of electron density waves parallel to the metal-dielectric medium interface [7, 8]. SPR system is relatively low-cost and only requires a simple optical setup, rendering a high potential to be suited for on-line/on-site monitoring [9-11].

The recognition of specific CTA molecules requires a highly selective material to provide such capability. Due to their easy synthesis procedures, low cost, and chemical and physical stability in harsh environments, MIPs provide a simple and cost-effective way to fabricate selective recognition elements suitable for chemo-sensors and biosensors [12]. Preparation of MIPs usually involves copolymerizing the template molecule and functional monomers (serving as ligands) with a cross-linker under suitable conditions. The type of cross-linker used influences the morphology of the polymer matrix, and stabilizes the recognition sites. During polymerization, the template and functional monomers will interact and self-assemble to form a polymer network. The MIP will be coated on the silver film of the glass sensor chip with silver film and the template molecule is then removed from the polymer matrix to create complementary three-dimensional cavities for the template. SPR sensors coupled with MIP has been successfully applied in analysing endotoxins [13], waterborne virus [14] and dyeing agents [15] in water.

In this study, an SPR sensor is presented using MIP as the recognition sites for the detection of CTA simulant parathion-methyl. Silver is selected as the SPR coating material since it is known to be more sensitive to changes in refractive indices [16] and reflects more distinctive plasmon resonance bands than gold [17]. The potential of online/on-site application of the developed SPR sensor is further discussed.

\section{Reagents and materials}

\section{Materials and Methods}

Analytical grade Parathion-methyl and functional monomer methacrylic acid (MAA) (99\%) were purchased from Sigma-Aldrich (Singapore). Absolute ethanol solvent was obtained from VWR Singapore Pte Ltd. and of analytical grade. Initiator 2, 2-azobis (2-methylpropionitrile) (AIBN) (99\%) was purchased from Sinopharm Chemical Reagent Co. Ltd. (China) while cross-linker divinylbenzene $(>50 \%)$ was purchased from Tokyo Chemical Industry Co. Ltd. (Japan). Deionised water (18.2 M , ultrapure) was purified using Milli-Q Integral Water Purification System from Merck Millipore while the index matching oil $(\boldsymbol{\eta}=1.65)$ used was provided by PhotonicSys Ltd. (Israel).

\section{Apparatus and instruments}

The SPR system and SPR analysis software (Version: Feb 2016) were from PhotonicSys Ltd. (Israel) and the 40-nm silver film sensor chips were sputter-coated and prepared by the company. The SPR system, as shown in Figure 1, is compact in size with $\mathrm{L} * \mathrm{~W} * \mathrm{H}$ of $8.5 * 4.5 * 4.5$ inch. It uses a diverging laser beam as the light source to illuminate the entire sensor surface in Kretschmann-Raether configuration $[18,19]$. A CCD detector is employed to monitor the pattern of dark intensity line on bright background which is corresponding to the SPR dip at an angular range depending on the refractive index of the adjacent analyte [20]. A high precision of SPR signal is subsequently achieved by a forward-projection algorithm based on Radon transform for two-dimensional surface plasmon imaging [21].

For ultra-sonication, the Elmasonic S30H sonicator used was obtained from Elma Schmidbauer GmbH (Germany). The LM530R orbital shaking incubator utilized was purchased from Yihder Technology Co. Ltd. (Taiwan) while the FINEVORTEX vortex mixer was obtained from FINEPCR (South Korea). 


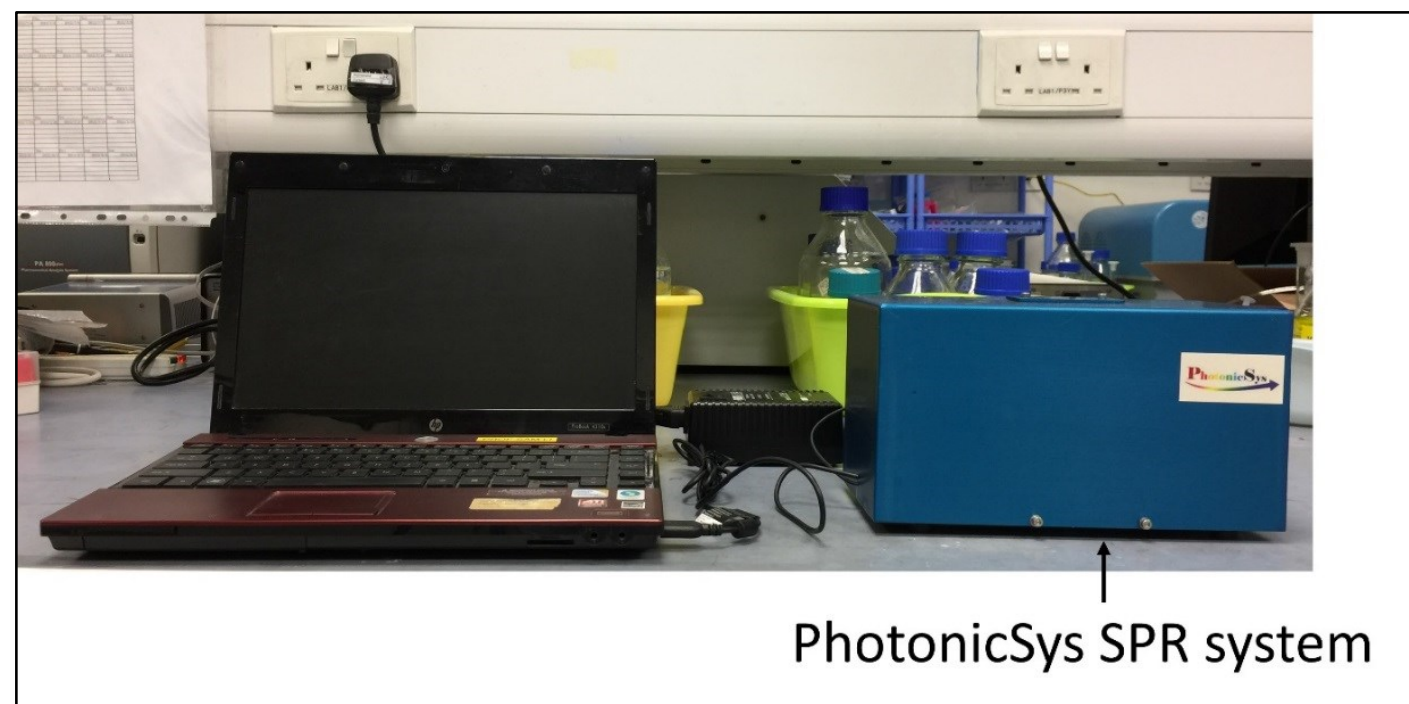

Figure 1. Photo of SPR instrument from PhotonicSys Ltd. connected to a notebook computer via USB

\section{Preparation of MIP sensor chips}

The MIP polymer comprises four components: MAA as functional monomer, DVB as cross-linker, AIBN as radical initiator and parathion methyl as template molecules. The mechanism behind MIP recognition is based on a combination of bonding. The carboxylic acid in MAA provides hydrogen-bonding donor, while DVB offers better stability of polymer rigidity and hydrophobic interaction with the template molecules.

Molecularly imprinted polymer was prepared by mixing $40 \mu \mathrm{L}$ of $0.1 \mathrm{M}$ parathion-methyl, $5 \mu \mathrm{L}$ of MAA, $25 \mu \mathrm{L}$ of DVB and $0.5 \mathrm{mg}$ of AIBN in $1.5 \mathrm{~mL}$ centrifuge tube with $100 \mu \mathrm{L}$ absolute ethanol. The mixture was ultra-sonicated for 10 minutes to allow thorough mixing. Subsequently, $10 \mu \mathrm{L}$ of the MIP solution was drop-coated on a silver sensor chip, which was placed in the oven at $60{ }^{\circ} \mathrm{C}$ for 6 hours to allow polymerization.

The MIP chip was then soaked in absolute ethanol and left in the orbital shaker for overnight (8-10 hours) to remove the template parathion-methyl molecule from its binding sites in the polymer matrix, shown in Figure 2. The MIP chip was stored in absolute ethanol before measurement to prevent degradation and oxidation of the silver layer. Non-imprinted polymer (NIP) sensor chips were prepared using the same preparation method but without template parathion-methyl.

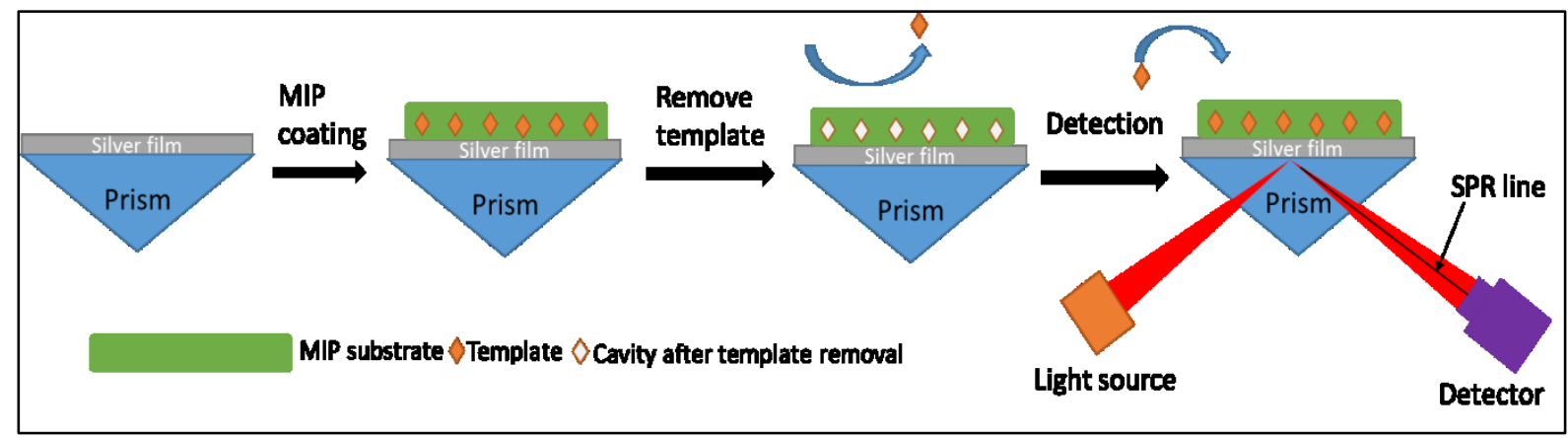

Figure 2. Schematic representation of MIP sensor design 


\section{Preparation of sample solutions}

A 100-ppm parathion methyl solution was prepared by diluting stock solution into a $100-\mathrm{mL}$ volumetric flask with ultrapure water made up to the $100-\mathrm{mL}$ mark. All sample solutions $(10 \mathrm{~mL}$ each) were prepared accordingly by diluting appropriate volumes of the stock solution in centrifuge sample tubes.

\section{SPR sensing procedure}

The SPR sensing procedure included the following steps, as illustrated in Figure 3. Firstly, SPR prism was wiped and cleaned with ethanol to remove any dirt or oil residuals. A small amount (approx. $50 \mu \mathrm{L}$ ) of RI matching oil was then applied on the prism. The MIP sensor chip was rinsed with ethanol and followed by deionised water before drying with nitrogen gas.

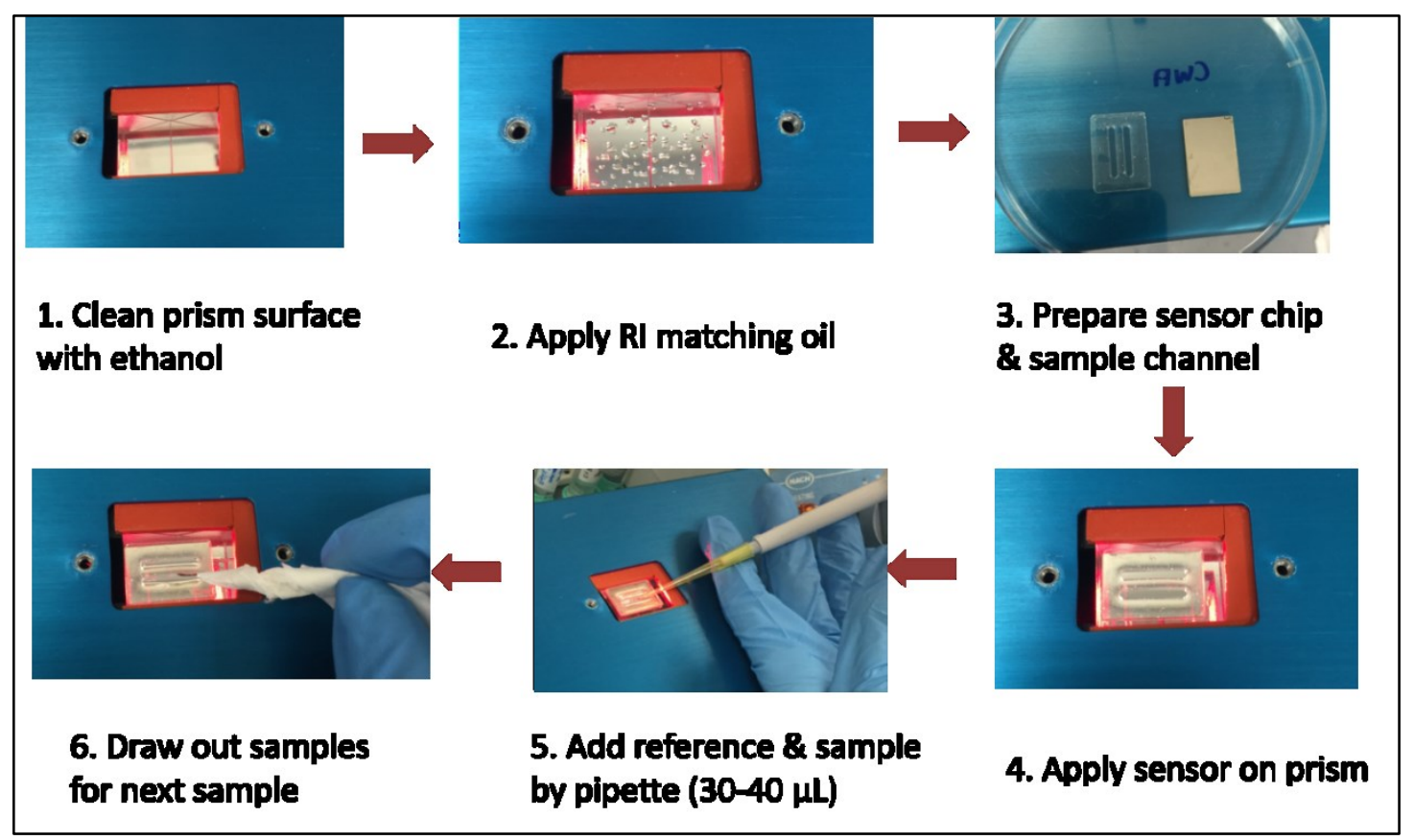

Figure 3. Experimental operation of SPR sensing

The MIP chip was mounted onto the prism by firstly placing the chip on its edge over the prism then carefully lowering it in place using a pair of forceps. It was important to ensure that no dark regions or lines were observed from the camera image. A polydimethylsiloxane (PDMS) sample holder with two identical channels was subentry applied onto the MIP sensor chip and gently pressed to form a sensing substrate.

A reference solution (deionised water) and a sample solution with $30-40 \mu \mathrm{L}$ were added into left and right channels. The channels were rinsed thrice with the respective solution before measurement. The regions of interest (ROIs) were defined by choosing the rectangle cursor and draw the ROI rectangle around the dark line. After each measurement, the solutions were drawn out by a tissue paper on the edge of the channels before adding a new solution.

The software interface allowed the user to view real-time images of the plasmon resonance bands and perform runs based on the difference in RI between the analyte and reference against time [22]. The sensing performance was highly dependent on the image sensor and thus it required optimisation before measurements. The optimised values for image sensor of SPR system was shown in Table 1. 
Table 1. Attributes and their respective values of image sensor

\begin{tabular}{lc}
\hline Attributes & Value \\
\hline Brightness & 67 \\
Contrast & 1.28 \\
Exposure & 0.0625 \\
Focus & 50 \\
Gain and saturation & 0 \\
Sharpness & 39 \\
White Balance & 3000 \\
Zoom & 100 \\
\hline
\end{tabular}

\section{Characterization of MIP and NIP}

Both MIP and NIP were soaked in ethanol under same conditions to remove unreacted reagents and dried in a vacuum oven. The respective polymer was then mixed and ground with $\mathrm{KBr}$ in $0.99 \% \mathrm{w} / \mathrm{w}$ before being pressed into a transparent pellet. FT-IR spectra were collected using ALPHA FTIR Spectrometer (Bruker). The key infrared peaks for MIP included $3018 \mathrm{~cm}^{-1}$ (alkene), $2960 \mathrm{~cm}^{-1}$ (alkane), $2925 \mathrm{~cm}^{-1}$ (carboxylic acid), and $1700 \mathrm{~cm}^{-}$ ${ }^{1}$ (carbonyl), while key peaks for NIP included $3019 \mathrm{~cm}^{-1}$ (alkene), $2960 \mathrm{~cm}^{-1}$ (alkane), $2926 \mathrm{~cm}^{-1}$ (carboxylic acid), and $1699 \mathrm{~cm}^{-1}$ (carbonyl).

\section{Detection time}

\section{Results and Discussion}

The SPR sensor in this study was a static-mode sensor which depended on the diffusion of targeted molecules into the cavity of MIP through either binding or space or both interactions. Figure 4a illustrates a real-time image of the SPR sensor of two channel signals. On the left was SPR image of deionised water as the reference, while on the right was SPR image of parathion-methyl as the analyte. Figure $4 \mathrm{~b}$ is an example of equivalent time of RI signal of the detection of $8 \mathrm{ppm}$ parathion methyl. RI signal increased until it reached a plateau at 300 seconds, i.e. 5 minutes. Similar RI response patterns were observed; therefore 5 minutes was chosen for each test.

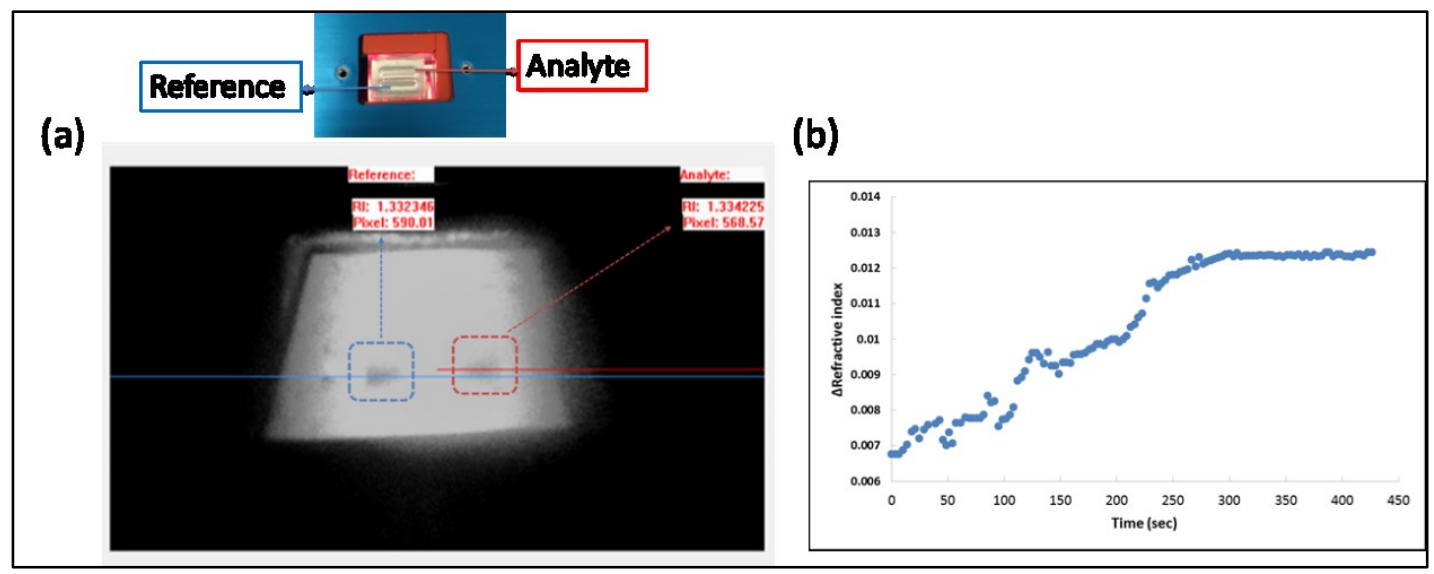

Figure 4. (a) Real-time image of SPR sensing of parathion-methyl and (b) refractive index response relative to time with 8 ppm parathion methyl 

WATER

\section{Detection of parathion methyl}

The wavelength of light or the incidence angle at which the SPR is excited, are strong functions of the refractive index of the dielectric medium adjacent to the metal surface, i.e. silver film. The dielectric medium can be a fluid such as water or any other fluids with varying refractive index (RI) due to variations in the concentration in water [22]. The current version of the PhotonicSys SPR system can detect down to $10^{-6}$ refractive index units (RIU).

Different concentration of parathion-methyl was prepared and spiked into water samples before measurements. The RI of molecularly imprinted polymers sensing and non-imprinted polymers sensing were compared. As can be seen from Figure 5, non-imprinted polymer (NIP) showed no apparent signal changes from low concentration to high concentration, whereas MIP showed increased SPR signals $(\Delta \mathrm{RI})$ from $2 \mathrm{ppm}$ to $30 \mathrm{ppm}$ and a plateau was observed above $30 \mathrm{ppm}$. As such, the linear range for the developed SPR sensor was determined to be $2-30 \mathrm{ppm}$ with a good correlation $\left(\mathrm{R}^{2}=0.8783\right)$. The limit of detection (LOD), based on the standard deviation of the response and the slope, was calculated to be $13.8 \mathrm{ppm}$ from the calibration curve.

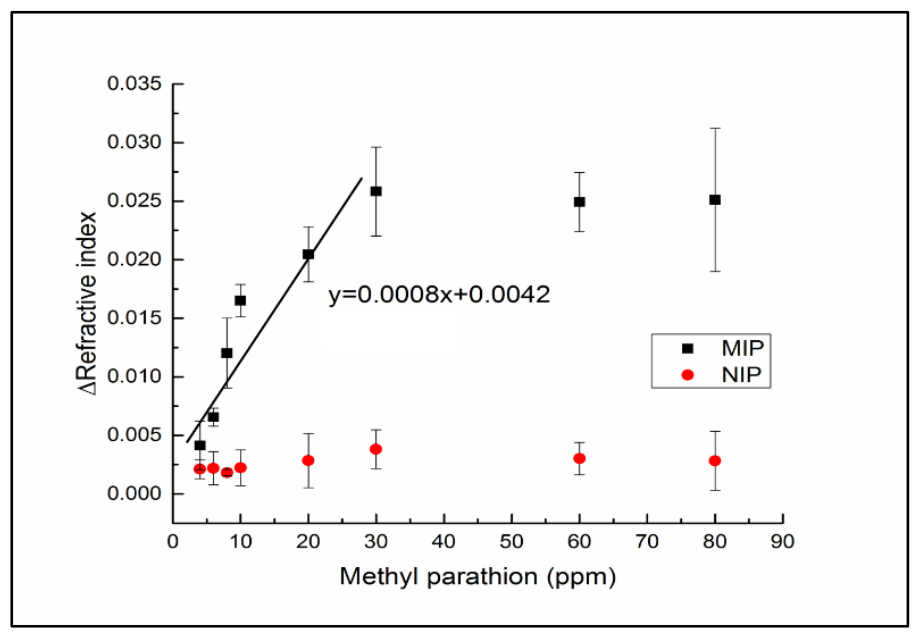

Figure 5. SPR refractive index responses on both imprinted molecular polymer (MIP) and non-imprinted polymer (NIP) toward the injection of different concentrations of methyl parathion in water

\section{Conclusion}

A fast responding ( $\sim 5 \mathrm{~min})$ SPR sensor based on MIP recognition for the detection of CTA simulant methyl parathion in water has been developed successfully. Due to the portability and fast responding capability, the MIP sensor can be easily deployed for on-site/on-line detection of toxic compounds in water. This method can be easily transferred to measure other organophosphorus compounds in water by adding the organophosphorus compounds as MIP templates. Improvement of sensitivity of SPR sensor can be improved by a flow SPR system. In contrast to the static system, where the interaction is only dependent on the diffusion, a flow SPR system will provide an everrefreshing interaction of targeted molecules with the developed MIP system. Therefore, the sensitivity can be significantly enhanced. Such flow SPR system will be developed and further tested in our future studies.

\section{Acknowledgement}

This research grant (1301-IRIS-021) is supported by the Singapore National Research Foundation under its Environment \& Water Research Programme and administered by PUB, Singapore's National Water Agency.

\section{References}

1. Chenau, J., Fenaille, F., Simon, S., Filali, S., Volland, H., Junot, C., Carniel, E. and Becher, F. (2014). Detection of Yersinia pestis in environmental and food samples by intact cell immunocapture and liquid chromatography-tandem mass spectrometry. Analytical Chemistry, 86(12): 6144 - 6152. 
2. Green, U., Kremer, J. H., Zillmer, M. and Moldaenke, C. (2003). Detection of chemical threat agents in drinking water by an early warning real- time biomonitor. Environmental Toxicology, 18(6): $368-374$.

3. Zhang, J. and Lee, H. K. (2006). Application of liquid-phase microextraction and on-column derivatization combined with gas chromatography-mass spectrometry to the determination of carbamate pesticides. Journal of Chromatography A, 1117(1): 31 - 37.

4. Sanagi, M. M., Mokhtar, S. U., Wan Ibrahim, W. A. and Miskam, M. (2011). Determination of organophosphorus pesticides by dispersive liquid-liquid microextraction coupled with gas chromatographyelectron capture detection. Malaysian Journal of Analytical Sciences, 15(2): 232 - 239.

5. Chang, S. Y., Tseng, W. L., Mallipattu, S. and Chang, H. T. (2005). Determination of small phosphoruscontaining compounds by capillary electrophoresis. Talanta, 66(2): $411-421$.

6. Tankiewicz, M., Fenik, J. and Biziuk, M. (2011). Solventless and solvent-minimized sample preparation techniques for determining currently used pesticides in water samples: A review. Talanta, 86: 8-22.

7. Homola J. and Piliarik M. (2006) Surface plasmon resonance (SPR) sensors. In: Homola J. (eds) Surface plasmon resonance based sensors. Springer Series on Chemical Sensors and Biosensors. Springer, Berlin, Heidelberg.

8. Abdulhalim, I., Zourob, M. and Lakhtakia, A. (2008). Surface plasmon resonance for biosensing: A minireview. Electromagnetics, 28(3): $214-242$.

9. Yao, G. H., Liang, R. P., Huang, C. F., Wang, Y. and Qiu, J. D. (2013). Surface plasmon resonance sensor based on magnetic molecularly imprinted polymers amplification for pesticide recognition. Analytical Chemistry, 85(24): $11944-11951$.

10. Zhang, P., Chen, Y. P., Wang, W., Shen, Y. and Guo, J. S. (2016). Surface plasmon resonance for water pollutant detection and water process analysis. TrAC Trends in Analytical Chemistry, 85: 153 - 165.

11. Olaru, A., Bala, C., Jaffrezic-Renault, N. and Aboul-Enein, H. Y. (2015). Surface plasmon resonance (SPR) biosensors in pharmaceutical analysis. Critical Reviews in Analytical Chemistry, 45(2): 97 - 105.

12. Shrivastav, A. M., Usha, S. P. and Gupta, B. D. (2016). Fiber optic profenofos sensor based on surface plasmon resonance technique and molecular imprinting. Biosensors and Bioelectronics, 79: $150-157$.

13. Altintas, Z., Abdin, M. J., Tothill, A. M., Karim, K. and Tothill, I. E. (2016). Ultrasensitive detection of endotoxins using computationally designed nanoMIPs. Analytica Chimica Acta, 935: 239 - 248.

14. Altintas, Z., Gittens, M., Guerreiro, A., Thompson, K. A., Walker, J., Piletsky, S. and Tothill, I. E. (2015). Detection of waterborne viruses using high affinity molecularly imprinted polymers. Analytical Chemistry, 87(13): $6801-6807$.

15. Dong, J., Peng, Y., Gao, N., Bai, J., Ning, B., Liu, M. and Gao, Z. (2012). A novel polymerization of ultrathin sensitive imprinted film on surface plasmon resonance sensor. Analyst, 137(19): 4571 - 4576.

16. Becker, J. (2012). Plasmons as sensors. Springer Science \& Business Media.

17. Lee, K. S. and El-Sayed, M. A. (2006). Gold and silver nanoparticles in sensing and imaging: sensitivity of plasmon response to size, shape, and metal composition. The Journal of Physical Chemistry B, 110(39): 19220 $-19225$.

18. Isaacs, S. and Abdulhalim, I. (2015). Long range surface plasmon resonance with ultra-high penetration depth for self-referenced sensing and ultra-low detection limit using diverging beam approach. Applied Physics Letters, 106(19): 193701.

19. Karabchevsky, A., Tsapovsky, L., Marks, R. S. and Abdulhalim, I. (2013). Study of immobilization procedure on silver nanolayers and detection of estrone with diverged beam surface plasmon resonance (SPR) imaging. Biosensors, 3(1): $157-170$.

20. Karabchevsky, A., Karabchevsky, S. and Abdulhalim, I. (2011). Fast surface plasmon resonance imaging sensor using Radon transform. Sensors and Actuators B: Chemical, 155(1): $361-365$.

21. Karabchevsky, A., Karabchevsky, S. and Abdulhalim, I. (2011). Nanoprecision algorithm for surface plasmon resonance determination from images with low contrast for improved sensor resolution. Journal of Nanophotonics, 5(1): 051813 - 051813.

22. PhotoicSys (2015). SPR system user manual (Version 1.0). 